\title{
Criptógamos do Parque Estadual das Fontes do Ipiranga, São Paulo, SP, Brasil. Pteridophyta: 10. Hymenophyllaceae
}

\author{
Regina Yoshie Hirai ${ }^{1,2}$ e Jefferson Prado ${ }^{1}$
}

Recebido: 17.05.2011; aceito: 27.10.2011

\begin{abstract}
Cryptogams from "Parque Estadual das Fontes do Ipiranga", São Paulo, SP State, Brazil. Pteridophyta: 10. Hymenophyllaceae). A floristic survey of the family Hymenophyllaceae was carried out in the "Parque Estadual das Fontes do Ipiranga (PEFI)". Six genera (Abrodictyum, Didymoglossum, Hymenophyllum, Polyphlebium, Trichomanes, and Vandenboschia) and nine species were reported. Four species of Hymenophyllum: Hymenophyllum caudiculatum Mart., Hymenophyllum hirsutum (L.) Sw., Hymenophyllum microcarpum Desv., and Hymenophyllum polyanthos (Sw.) Sw., and one species for each other genera: Abrodictyum rigidum (Sw.) Ebihara \& Dubuisson, Didymoglossum reptans (Sw.) C. Presl, Polyphlebium angustatum (Carmich.) Ebihara \& Dubuisson, Trichomanes polypodioides Raddi, and Vandenboschia radicans (Sw.) Copel. Identification keys for genera and species, as well as descriptions, geographical distribution, comments, and illustrations for some studied taxa are presented.
\end{abstract}

Key words: Atlantic forest, ferns, floristic survey, Hymenophyllum, Trichomanes

RESUMO - (Criptógamos do Parque Estadual das Fontes do Ipiranga, São Paulo, SP, Brasil. Pteridophyta: 10. Hymenophyllaceae). O levantamento florístico da família Hymenophyllaceae foi realizado no Parque Estadual das Fontes do Ipiranga (PEFI). Foram registrados seis gêneros (Abrodictyum, Didymoglossum, Hymenophyllum, Polyphlebium, Trichomanes e Vandenboschia) e nove espécies (quatro spp. de Hymenophyllum: Hymenophyllum caudiculatum Mart., Hymenophyllum hirsutum (L.) Sw., Hymenophyllum microcarpum Desv., Hymenophyllum polyanthos (Sw.) Sw., e os demais gêneros uma espécie cada: Abrodictyum rigidum (Sw.) Ebihara \& Dubuisson, Didymoglossum reptans (Sw.) C. Presl, Polyphlebium angustatum (Carmich.) Ebihara \& Dubuisson, Trichomanes polypodioides Raddi e Vandenboschia radicans (Sw.) Copel.). São apresentadas chaves para identificação para os gêneros e espécies, bem como descrições, distribuição geográfica, comentários e ilustrações para alguns dos táxons estudados.

Palavras-chave: Floresta Atlântica, Hymenophyllum, levantamento florístico, samambaias, Trichomanes

\section{Introdução}

O presente estudo é parte do levantamento florístico das samambaias e licófitas do Parque Estadual das Fontes do Ipiranga (PEFI), que foi iniciado por Hoehne et al. (1941). Até o momento foram publicados os tratamentos para 14 das 24 famílias encontradas na área do Parque (Prado 2004a, b, c, d, e, f, g, 2006a, b), Prado \& Hirai $(2008,2010)$ e Prado et al. (2010).

No sistema de classificação de Tryon \& Tryon (1982) apenas dois gêneros eram reconhecidos na família Hymenophyllaceae: Hymenophyllum Sm. e Trichomanes L. Posteriormente, no sistema de Kramer \& Green (1990), a família foi tratada em duas subfamílias, seguindo os conceitos de Iwatsuki (1984, 1990): Hymenophylloideae, com sete gêneros (Cephalomanes C. Presl, Crepidomanes (C. Presl) C. Presl, Hymenoglossum C. Presl, Hymenophyllum, Serpyllopsis Bosch, Sphaerocionium C. Presl e Trichomanes) e Cardiomanioideae, com um único gênero (Cardiomanes C. Presl).

Na atual classificação de Smith et al. (2006, 2008), baseada em filogenia molecular, Hymenophyllaceae é reconhecida como um família distinta, monofilética e basal no clado das samambaias leptosporangiadas. Além disso, pertence à classe Polypodiopsida e ordem Hymenophyllales. Esta classificação segue a circunscrição para a família conforme apresentada em Ebihara et al. (2006), contendo

1. Instituto de Botânica, Herbário SP, Caixa Postal 68041, 04045-972 São Paulo, SP, Brasil

2. Autor para correspondência: regina.hirai@gmail.com 
nove gêneros: Hymenophyllum, Didymoglossum Desv.,Crepidomanes, Polyphlebium Copel., Vandenboschia Copel., Abrodictyum C. Pres1, Trichomanes, Cephalomanes e Callistopteris Copel.

Para a flora do Estado de São Paulo não há nenhum trabalho específico com a família. Informações sobre as espécies de Hymenophyllaceae são encontradas apenas em trabalhos florísticos pontuais, como por exemplo, em Boldrin \& Prado (2007), Nóbrega \& Prado (2008) e checklists como em Salino (1996), Salino \& Almeida (2008), Prado (2004h), Prado \& Labiak (2009), etc.

O objetivo do presente artigo é apresentar o tratamento taxonômico para a família Hymenophyllaceae na área do PEFI.

\section{Material e métodos}

O material foi coletado de acordo com as técnicas descritas em Fidalgo \& Bononi (1984) e encontra-se depositado no Herbário do Instituto de Botânica (SP) e no Herbário do Departamento de Botânica da Universidade de São Paulo (SPF). Também existem duplicatas das espécies estudadas no Herbário da Universidade Estadual de Campinas (UEC).

Os dados sobre a caracterização e localização do Parque Estadual das Fontes do Ipiranga (PEFI), bem como o planejamento desta flora, foram apresentados em Melhem et al. (1981) e Milanez et al. (1990).

O número que antecede o nome da família, no título deste trabalho, corresponde à numeração das famílias apresentadas em Prado (2004a). A chave para as famílias, incluindo Hymenophyllaceae, também foi publicada por Prado (2004a).

Para o tratamento taxonômico dos gêneros na família Hymenophyllaceae foram utilizados a classificação de Ebihara et al. (2006). Os táxons estudados estão apresentados em ordem alfabética de gêneros e espécies.

A abreviação dos nomes dos autores de táxons está de acordo com Pichi-Sermolli (1996).

Material adicional foi utilizado para complementação das descrições, no caso em que determinadas estruturas não estavam presentes no material coletado no PEFI.

São apresentadas ilustrações apenas para as espécies que apresentam maior grau de dificuldade para identificação. Para as demais espécies, que são bastante comuns em Mata Atlântica, já existem ilustrações disponíveis na literatura e optou-se por não ilustrá-las.

\section{Resultados e Discussão}

No estudo realizado por Hoehne et al. (1941) foram listados dois gêneros e seis espécies nativas na área do PEFI: Hymenophyllum caudiculatum Mart., H. ciliatum (Sw.) Sw., H. polyanthos Sw., Trichomanes anadromum Rosenst., T. rigidum $\mathrm{Sw}$. e T. tenerum Spring (= Polyphlebium angustatum (Carmich.) Ebihara \& Dubuisson), além de duas espécies cultivadas (Hymenophyllum trichophyllum Kunth e Trichomanes accedens C. Presl), trazidas da Estação Biológica do Alto da Serra.

Hymenophyllum ciliatum, $H$. trichophyllum e Trichomanes accendes relatadas por Hoehne et al. (1941), provavelmente são identificações equivocadas, uma vez que essas espécies são conhecidas apenas para a região amazônica (Windisch 2010). Por outro lado, T. anadromum, que é uma espécie comum na Mata Atlântica, não foi registrada para a área do Parque.

No atual levantamento realizado no PEFI foram encontrados seis gêneros e nove espécies, a saber: quatro espécies de Hymenophyllum (H. caudiculatum Mart., H. hirsutum (L.) Sw., H. microcarpum Desv., H. polyanthos (Sw.) Sw.) e uma espécie de cada um dos demais gêneros (Abrodictyum rigidum (Sw.) Ebihara \& Dubuisson, Didymoglossum reptans (Sw.) C. Pres1, Polyphlebium angustatum (Carmich.) Ebihara \& Dubuisson, Trichomanes polypodioides Raddi e Vandenboschia radicans (Sw.) Copel).

Hymenophyllaceae

Plantas terrestres, epífitas ou rupícolas. Caule delgado, reptante, fibroso, ou às vezes subereto a ereto e um pouco mais robusto, protostélico; lâmina com uma camada de células em espessura no tecido laminar (com raras exceções); sem estômatos e cutícula ou esta bastante reduzida; geralmente sem escamas sobre a lâmina, às vezes com tricomas. Soro marginal, indúsio cônico, tubular, ou bivalvado, com receptáculo alongado (nos trichomanoides), projetando-se do indúsio (exserto); esporângio com maturação basípeta (maturando em sucessão do ápice à base), cada um com ânulo oblíquo, não interrompido pelo pedicelo; esporos clorofilados, globosos, triletes. Gametófitos filamentosos ou semelhantes a fitas, geralmente reproduzindo-se por fragmentação ou por gemas; $\mathrm{x}=11,12,18,28,32,33,34,36$, e talvez outros (Smith et al. 2006).

De acordo com Smith et al. (2006), a família atualmente compreende nove gêneros, cerca de 
600 espécies e distribui-se principalmente em regiões tropicais e subtropicais. Também ocorre no Paleotrópico. No Brasil, está representada por seis gêneros e 85 espécies, que ocorrem principalmente na Mata Atlântica e Amazônia (Windisch 2010).

Chave para os gêneros de Hymenophyllaceae

1. Caule ereto a subereto Abrodictyum

1. Caule longo-reptante

2. Indúsio bivalvado .

2. Indúsio cônico ou tubular

3. Raízes ausentes; falsas vênulas presentes, paralelas às nervuras verdadeiras Hymenophyllum

3. Raízes presentes; falsas vênulas ausentes ou, se presentes, perpendiculares às nervuras verdadeiras (em algumas espécies de Trichomanes)

4. Raízes delgadas e poucas Polyphlebium

4. Raízes robustas e numerosas

5. Lâmina com pinas ou segmentos assimétricos; venação catadrômica; margens da lâmina glabras Vandenboschia

5. Lâmina com pinas ou segmentos simétricos; venação anadrômica; margens da lâmina com tricomas . Trichomanes

\section{Abrodictyum C. Pres1}

Plantas terrestres ou rupícolas. Caule ereto a subereto, delgado, ca. $2 \mathrm{~mm}$ diâm., com numerosas raízes robustas, tricomas localizados apenas no ápice do caule, pluricelulares, castanhos a enegrecidos; pecíolo 7-15 cm compr., agrupados ou mais ou menos distantes; lâmina $30 \times 18 \mathrm{~cm}$, linear-oval a subdeltóide, 2-pinada a 4-pinatífida, membranácea a cartácea; pinas ou pínulas anadrômicas; venação anadrômica (i.e., com a pínula proximal e/ou grupo de nervuras proximais de uma pina no lado acroscópico da fronde), falsas vênulas ausentes. Soros formados em nervuras laterais das frondes; indúsio cônico, ápice truncado, receptáculo longamente exserto.

Abrodictyum possui mais de 10 espécies, distribuídas em dois subgêneros (Abrodictyum e Pachychaetum (C. Presl) Ebihara \& K. Iwats.), ocorre nos trópicos (Ebihara et al. 2006). Segundo Windisch (2010), no Brasil ocorrem três espécies e uma em São Paulo.

Abrodictyum rigidum (Sw.) Ebihara \& Dubuisson, Blumea 51(2): 243. 2006 E Trichomanes rigidum Sw., Prodr.: 137. 1788.

Figura 1A, B

Plantas terrestres. Caule com raízes fibrosas, tricomas 1,0-1,8 mm compr., simples, aciculares, castanho-avermelhados a enegrecidos. Frondes
15-27 cm compr.; pecíolo 5-14 cm compr., cilíndrico, castanho-escuro, não alado, com tricomas 1,0-2,2 mm compr., simples, septados, filiformes, castanho-avermelhados; lâmina 10,7-13,0 × 5,0-7,5 cm, deltóide a lanceolada, às vezes oval, 2-pinado-pinatissecta ou pinado-bipinatissecta, cartácea, com tricomas esparsos semelhantes aos do pecíolo e outros diminutos, 0,2 $\mathrm{mm}$ compr., claviformes, principalmente abaxialmente; raque não alada ou estreitamente alada próximo ao ápice, com tricomas esparsos, semelhantes aos do pecíolo; pinas lanceoladas; últimos segmentos lineares, ápice agudo ou furcado, margens inteiras. Indúsio livre, com margem crenulada.

Material examinado: 1-X-1936, O. Handro s.n. (SP43039); 9-IV-1976, J.A. Corrêa 130 (SP).

Distribuição geográfica: Paleotrópico, México, Guatemala, Belize, Honduras, Nicarágua, Costa Rica, Panamá, Grandes e Pequenas Antilhas, Colômbia, Venezuela, Trinidad, Guiana, Suriname, Guiana Francesa, Equador, Peru, Bolívia e Brasil: Mato Grosso, Mato Grosso do Sul, Minas Gerais, Espírito Santo, Rio de Janeiro, São Paulo, Paraná, Santa Catarina e Rio Grande do Sul.

Abrodictyum rigidum é facilmente reconhecida na área do PEFI por se tratar da única espécie de Hymenophyllaceae com caule ereto a subereto. 
Além disso, é uma espécie que apresenta pecíolo não alado, lâmina geralmente deltóide a lanceolada e 2-pinado-pinatissecta ou pinado-bipinatissecta.

\section{Didymoglossum Desv.}

Plantas epífitas ou rupícolas. Caule longoreptante, geralmente ramificado, filiforme, até 0,5 mm diâm., raízes ausentes, densamente coberto com tricomas, pluricelulares, castanhoescuros; pecíolo geralmente reduzido, até $1 \mathrm{~cm}$ compr., equidistantes; lâmina $6 \times 6 \mathrm{~cm}$, elíptica a estreitamente oval, geralmente simples, ou às vezes lobada a pinatífida, membranácea; pinas ou pínulas catadrômicas; venação catadrômica (i.e., com a pínula proximal e/ou grupo de nervuras da pina proximal no lado basiscópico da fronde), falsas vênulas paralelas às nervuras verdadeiras. Soros geralmente formados nas nervuras apicais das frondes; indúsio cônico, ápice bilabiado ou às vezes truncado, geralmente com margens enegrecidas, receptáculo exserto.

Didymoglossum apresenta mais de 20 espécies, distribuídas em dois subgêneros (Didymoglossum e Microgonium (C. Presl) Ebihara \& K. Iwats.) e ocorre principalmente na região Neotropical (Ebihara et al. 2006). No Brasil ocorrem 12 espécies sendo cinco em São Paulo (Windisch 2010).

Didymoglossum reptans (Sw.) C. Presl, Hymenophyllacae: 23. 1843 ETrichomanes reptan Sw., Prodr.: 136. 1788.

Figura 1C-E

Plantas epífitas. Caule com tricomas 0,3-0,5 mm compr., aplanados, flexuosos, negros a castanhoavermelhados. Frondes 4-6 cm compr.; pecíolo 0,5-1,0 mm compr., subcilíndrico, enegrecido, não alado, com tricomas semelhantes aos do caule; lâmina 4,0-5,3 × 0,9-5,0 cm, lanceolada a oval ou elíptica, pinatissecta, pinatissecto-pinatífida, às vezes 2-pinatissecta, com tricomas negros, simples, furcados ou estrelados nas margens, também com tricomas diminutos, ca. 0,1 $\mathrm{mm}$ compr., principalmente sobre as nervuras abaxialmente; raque alada, com tricomas semelhantes aos do caule e tricomas diminutos semelhantes aos da lâmina, principalmente abaxialmente; últimos segmentos levemente lineares a deltóide, margens inteiras, ápice agudo. Indúsio exserto a levemente imerso no tecido laminar, com margem inteira e castanho-escura a negra.
Material examinado: 24-IV-1951, O. Handro 246 (SP, SPF).

Distribuição geográfica: México, Guatemala, Honduras, El Salvador, Nicarágua, Costa Rica, Panamá, Jamaica, Hispaniola, Colômbia, Venezuela, Trinidad, Guianas, Equador, Peru, Bolívia, Paraguai, Argentina e Brasil: Minas Gerais, São Paulo e Santa Catarina.

Didymoglossum reptans é distinto das outras espécies que ocorrem na área do PEFI pelas características utilizadas na chave para distinguir o gênero (ausência de raízes e presença de falsas vênulas entre as nervuras no tecido laminar). É uma espécie reconhecida por apresentar tricomas furcados e estrelados ocorrendo nas margens da lâmina, bem como pela margem do indúsio castanho-escura a negra.

\section{Hymenophyllum Sm.}

Plantas epífitas, terrestres ou rupícolas. Caule longo-reptante, geralmente ramificado, filiforme ou delgado, até $2 \mathrm{~mm}$ diâm., com poucas raízes delgadas, quase glabro ou esparsamente coberto com tricomas, pluricelulares (exceto no subg. Fuciformia, densamente coberto com tricomas), castanho-amarelados a castanho-escuros; pecíolo varia no comprimento, equidistantes; lâmina $165 \times 17 \mathrm{~cm}$, elíptica, oval ou subdeltóide, geralmente pinada a 4-pinada ou às vezes simples, membranácea; pinas ou pínulas anadrômicas; venação anadrômica. Soros formados em nervuras laterais das frondes; indúsio bivalvado, receptáculo incluso no indúsio.

Hymenophyllum possui ca. de 250 espécies, distribuídas em 10 subgêneros (Hymenophyllum, Sphaerocionium (C. Presl) C. Chr., Mecodium C. Presl ex Copel., Globosa (Prantl) Ebihara \& K. Iwats., Pleuromanes (C. Presl) Ebihara \& K. Iwats., Myrmecostylum (C. Presl) Ebihara \& K. Iwats., Hymenoglossum (C. Presl) R.M. Tryon \& A.F. Tryon, Fuciformia Ebihara \& K. Iwats., Diploöphyllum (Bosch) Ebihara \& K. Iwats. e Cardiomanes (C. Presl) Ebihara \& K. Iwats.), ocorrendo nos trópicos, bem como em regiões temperadas (Ebihara et al. 2006). De acordo com Windisch (2010), no Brasil ocorrem 29 espécies e três variedades, e em São Paulo 11 espécies e duas variedades. 


\section{Chave para as espécies de Hymenophyllum}

1. Caule com tricomas esparsos, concentrados principalmente nas articulações das raízes e pecíolo; lâmina glabra

2. Frondes 12,5-18,0 cm compr.; lâmina deltóide a deltóide-lanceolada; indúsio orbicular

2. Frondes 3-4(-6,5) cm compr.; lâmina oval a oblonga; indúsio oval H. caudiculatum

1. Caule com tricomas esparsos ao longo de toda sua extensão; lâmina pilosa

3. Frondes 5,0-8,0 cm compr.; pecíolo alado na metade superior; margens do indúsio com tricomas estrelados H. polyanthos

3. Frondes com 23,5 cm compr.; pecíolo não alado; margens do indúsio com tricomas simples

H. hirsutum

H. microcarpum

Hymenophyllum caudiculatum Mart., Icon. Pl. Crypt. 102, t. 67.1834.

Plantas epífitas. Caule com tricomas esparsos, concentrados principalmente nas articulações das raízes e pecíolo, 1-2 mm compr., simples, septados, castanho-avermelhados. Frondes 12,5-18,0 cm compr.; pecíolo 2-4 cm compr., cilíndrico, castanho, alado, glabro ou com poucos tricomas na base, semelhantes aos do caule; lâmina 9,0-14,5 × 4,5-8,0 cm, deltóide a deltóide-lanceolada, 3-pinatissecta, glabra; raque alada, glabra; últimos segmentos simples ou furcados, os segmentos apicais longos, 2-3 cm compr., quase caudados ou retos, margens inteiras, ápice arredondado ou emarginado. Indúsio parcialmente inserido no tecido laminar, orbicular, margem inteira, glabra.

Material examinado: 24-VII-1933, W. Hoehne 278 p.p. (SPF); 10-X-1940, O. Handro s.n. (SP44142).

Distribuição geográfica: Paraguai, Argentina, Chile e Brasil: Amazonas, Bahia, Minas Gerais, Rio de Janeiro, São Paulo, Paraná, Santa Catarina e Rio Grande do Sul.

Em relação às outras espécies de Hymenophyllum que ocorrem na área do PEFI, H. caudiculatum é a que possui distribuição mais restrita na América do Sul.

Hymenophyllum caudiculatum pode ser facilmente reconhecida por apresentar lâmina glabra e segmentos apicais geralmente longos, com 2-3 cm compr.

Hymenophyllum hirsutum (L.) Sw., J. Bot. (Schrader) 1800(2): 99. 1801 ETrichomanes hirsutum L. Sp. pl. 2: 1098. 1753.

Plantas epífitas. Caule cobertopor tricomas esparsos ao longo de toda sua extensão, 0,5-1,2 mm compr., simples, septados, castanho-amarelados. Frondes
5-8 cm compr.; pecíolo 0,5-2,0 cm compr., cilíndrico, castanho-claro, alado na metade superior, com tricomas estrelados e furcados, pedunculados; lâmina 4,5-5,0 × 2,0-3,0 cm, deltóide-lanceolada, 2-pinatissecta, densamente revestida por tricomas, geralmente estrelados pedunculados, nas nervuras em ambas as faces e margens; raque alada, com tricomas semelhantes aos da lâmina; últimos segmentos lineares, margens denticuladas com tricomas estrelados, ápice arredondado ou furcado. Indúsio inserido no tecido laminar, orbicular a oblongo, margem inteira, com tricomas estrelados.

Material examinado: 19-IX-1938, O. Handro s.n. (SP52527).

Distribuição geográfica: México, Guatemala, Belize, Honduras, Nicarágua, Costa Rica, Panamá, Grandes e Pequenas Antilhas, Colômbia, Venezuela, Trinidad, Guiana, Suriname, Guiana Francesa, Equador, Peru, Bolívia e Brasil: Pará, Ceará, Pernambuco, Bahia, Minas Gerais, Rio de Janeiro, São Paulo, Paraná, Santa Catarina e Rio Grande do Sul.

Hymenophyllum hirsutum é caracterizado por apresentar pecíolo alado na metade superior, tricomas estrelados em abundância sobre a raque, nervuras, em ambas as faces e margens da lâmina, bem como pela margem do indúsio com tricomas estrelados.

Hymenophyllum microcarpum Desv., Mém. Soc. Linn. Paris 6: 333. 1827.

Figura 1F-H

Plantas epífitas. Caule coberto com tricomas esparsos ao longo de toda sua extensão, 1-2 mm compr., simples, septados, castanho-amarelados. Frondes 23,5 cm compr.; pecíolo 7,5 cm compr., cilíndrico, castanho-escuro, não alado, com tricomas simples, furcados e 
estrelados pedunculados, castanho-amarelados; lâmina 17,2 × 7,5 cm, lanceolado-oval, 3-pinatissecta, densamente revestida com tricomas semelhantes aos do pecíolo, principalmente nas nervuras abaxialmente, margens com tricomas simples; raque alada, com tricomas estrelados pedunculados, principalmente abaxialmente; últimos segmentos lineares, margens onduladas, levemente apiculados. Indúsio levemente imerso na base, oval, oblongo, ápice agudo, margem levemente denticulada, com tricomas simples.

Material examinado: 24-VII-1933, W. Hoehne 278 p.p. (SPF).

Distribuição geográfica: México, Guatemala, Honduras, El Salvador, Nicarágua, Costa Rica, Panamá, Grandes Antilhas, Dominica, Colômbia, Venezuela, Guiana, Equador, Peru, Bolívia e Brasil: Rio de Janeiro, São Paulo, Paraná e Santa Catarina.

A espécie mais semelhante à Hymenophyllum microcarpum e que também ocorre na área do Parque é H. hirsutum. Esta última difere por apresentar pecíolo alado, lâmina densamente revestida por tricomas, geralmente estrelados pedunculados, nas nervuras, em ambas as faces e margens. Além disso, a margem do indúsio apresenta tricomas estrelados (vs. tricomas simples).

Hymenophyllum polyanthos (Sw.) Sw., J. Bot. (Schrader) 1800(2): 102. $1801 \equiv$ Trichomanes polyanthos Sw., Prodr.: 137. 1788.

Plantas epífitas. Caule com tricomas esparsos, concentrados principalmente nas articulações do pecíolo e raízes, 0,3-0,5 mm compr., castanho-escuros. Frondes 3-4(-6,5) cm compr.; pecíolo 0,4-0,5 cm compr., cilíndrico, castanho-escuro, alado, glabro; lâmina 2,6-3,5(-6,0) × 1,2-1,5(-2,0), 2-pinatissecta, oval, oblonga ou oval-lanceolada, glabra ou com tricomas diminutos esparsos, 0,1-0,2 mm compr., abaxialmente; raque alada, glabra ou com tricomas diminutos esparsos semelhantes aos da lâmina; últimos segmentos lineares, margens inteiras e planas, ápice emarginado. Indúsio levemente imerso no tecido laminar, oval, ápice obtuso, margem inteira, glabra.

Material examinado: 30-IV-1974, J.A. Corrêa 49 (SP).

Material adicional examinado: BRASIL. SÃo PAULO: Campos do Jordão, Parque Estadual de Campos do Jordão, trilha da Cachoeira, 1.430 m, 21-III-1996, J. Prado \& M.P. Marcelli 786 (SP).
Distribuição geográfica: África, Ásia, México, Guatemala, Belize, Honduras, El Salvador, Nicarágua, Costa Rica, Panamá, Grandes e Pequenas Antilhas, Colômbia, Venezuela, Trinidad, Guiana, Suriname, Guiana Francesa, Equador, Peru, Bolívia e Brasil: Amazonas, Acre, Roraima, Rondônia, Amapá, Pará, Ceará, Pernambuco, Bahia, Mato Grosso, Goiás, Mato Grosso do Sul, Minas Gerais, Espírito Santo, Rio de Janeiro, São Paulo, Paraná, Santa Catarina e Rio Grande do Sul.

Hymenophyllum polyanthos é uma espécie bastante variável morfologicamente, até mesmo por apresentar uma distribuição geográfica ampla pelos continentes (Mickel \& Smith 2004). É uma espécie caracterizada pela presença de um pecíolo alado e glabro. Entre as espécies que ocorrem na área do PEFI, $H$. polyanthos é mais semelhante à $H$. caudiculatum e podem ser separadas pelas características utilizadas na chave.

\section{Polyphlebium Copel.}

Plantas epífitas ou rupícolas. Caule longo-reptante, geralmente ramificado, filiforme, 0,1-0,8 mm diâm., com poucas raízes delgadas, densamente coberto com tricomas, pluricelulares, castanho-claros; pecíolo 0,3-5,5 cm compr., equidistantes; lâmina $30,0 \times 6,5 \mathrm{~cm}$, oval a estreitamente oval, pinada a 4-pinada, membranácea; pinas ou pínulas anadrômicas; venação anadrômica, falsas vênulas ausentes. Soros com indúsios formados em nervuras laterais das frondes; indúsio cônico, ápice expandido, receptáculo longamente exserto.

Ocorre principalmente em regiões temperadas do hemisfério sul e florestas montanhosas em baixas altitudes, com ca. de 15 espécies (Ebihara et al. 2006). No Brasil ocorrem quatro espécies, e três em São Paulo (Windisch 2010).

Polyphlebium angustatum (Carmich.) Ebihara \& Dubuisson, Blumea 51(2): 240.2006 $\equiv$ Trichomanes angustatum Carmich., Trans. Linn. Soc. London 12: 513.1819.

Figura 1I-J

Plantas epífitas. Caule com tricomas 0,2-0,5 mm compr., aplanados, flexuosos, castanho-amarelados a castanhos. Frondes 5-11 cm compr.; pecíolo 0,5-1,2 cm compr., cilíndrico, não alado; lâmina 4,5-10,2 × 1,2-3,0 cm, oval ou lanceolada, 1-pinado-bipinatissecta ou 1-pinado-tripinatissecta, gradualmente reduzida em 
direção à base, glabra; raque não alada, com tricomas diminutos, 0,1-0,2 mm compr., principalmente nas nervuras abaxialmente, castanho-avermelhados; pinas oblongo-lanceoladas, pinas proximais reduzidas e muitas vezes vestigiais; últimos segmentos lineares, margens inteiras, ápice arredondado ou furcado. Indúsio livre, ápice truncado ou lobado, margens inteiras a levemente crenadas.

Material examinado: 26-IV-1951, O. Handro 247 (SP); $23^{\circ} 36^{\prime} \mathrm{S}, 46^{\circ} 38^{\prime} \mathrm{W}, 810 \mathrm{~m}$, G. Eiten et al. 2050 (SP); 2340'18'S, 46³8'00”'W, 700 m, 1-VIII-2008, J. Prado \& R. Y. Hirai 2004 (SP).

Distribuição geográfica: México, Costa Rica, Guatemala, Honduras, Grandes Antilhas, Colômbia, Bolívia, Paraguai, Uruguai, Nordeste da Argentina, Tristan da Cunha, Sudeste e Sul do Brasil: Minas Gerais, Espírito Santo, Rio de Janeiro, São Paulo, Paraná, Santa Catarina e Rio Grande do Sul.

Na área do PEFI, Polyphlebium angustatum é uma planta epífita encontrada sobre o caule de Alsophila setosa Kaulf. Esta espécie é geralmente confundida com Polyphlebium capillaceum (L.) Ebihara \& Dubuisson, que difere principalmente pelos últimos segmentos que são mais estreitos (0,1-0,4 mm larg. vs. 0,5-0,7 mm larg.) (Mickel \& Smith 2004). Além disso, P. capillaceum ocorre na América Central, Antilhas, Colômbia, Venezuela, Equador e Peru, entretanto não chega ao Brasil (Mickel \& Smith 2004).

\section{Trichomanes L.}

Plantas geralmente terrrestres, às vezes epífitas. Caule longo-reptante, geralmente delgado a robusto, 1-5 mm diâm., com numerosas raízes robustas, esparsamente a densamente coberto com tricomas, pluricelulares, castanhos a enegrecidos; pecíolo até $30 \mathrm{~cm}$ compr., geralmente próximos, às vezes mais ou menos distantes; lâmina $70 \times 25 \mathrm{~cm}$, oval a linear-oval, pinatissecta a pinada, com pinas ou segmentos simétricos, membranácea; pinas ou pínulas anadrômicas; venação geralmente catadrômica ou anadrômica (em T. scandens e T. anadromum), às vezes com tricomas unicelulares ou pluricelulares, falsas vênulas presentes em algumas espécies (e estas perpendiculares às nervuras verdadeiras), margens com tricomas simples ou estrelados. Soros com indúsios formados em nervuras laterais das frondes ou nas nervuras apicais das frondes; indúsio cônico, ápice truncado, às vezes expandido, receptáculo em geral longamente exserto.
Trichomanes ocorre principalmente no neotrópico e pelo menos uma espécie chega ao continente africano. Possui mais de 30 espécies, distribuídas em quatro subgêneros (Davalliopsis (Bosch) Ebihara \& K. Iwats., Feea (Bory) Hook., Lacostea (Bosch) C. Chr., Trichomanes) (Ebihara et al. 2006). Segundo Windisch (2010), no Brasil ocorrem 33 espécies e no Estado de São Paulo oito espécies.

Trichomanes polypodioides L., Sp. pl.: 1098. 1753.

Plantas epífitas. Caule com tricomas 1,5-2,5 mm compr., simples, às vezes furcados e pedunculados, aplanados, flexuosos, castanho-amarelados. Frondes 6-22 cm compr.; pecíolo 0,5-3,5 cm compr., cilíndrico, alado na porção superior, com tricomas furcados, estrelados, pedunculados, às vezes sésseis; lâmina 5,5-16,0 × 1,7-3,8 cm, lanceolada a linear-lanceolada, pinatissecta a pinatissecto-pinatífida, revestida por tricomas furcados, estrelados, sésseis, às vezes curto-pedunculados, sobre as nervuras, principalmente abaxialmente e margens, com tricomas diminutos esparsos, 0,1 mm compr., sobre nervuras abaxialmente; raque alada, tricomas semelhantes aos da lâmina. Indúsio imerso no tecido laminar, margem inteira a levemente crenada, glabra.

Material examinado: 30-VI-1936, O. Handro s.n. (SP44450); 2-IX-1976, P.H. Davis et al. 60427 (UEC); mata do lado esquerdo, adjacente ao Castelinho, 20-X-2003, J. Prado \& D.M. Vital 1452 (SP); trilha atrás do novo prédio do Herbário, 5-II-2004, J. Prado 1456 (SP);

Distribuição geográfica: México, Guatemala, Belize, Honduras, Nicarágua, Costa Rica, Panamá, Grandes e Pequenas Antilhas, Trinidad, Colômbia, Venezuela, Guiana, Suriname, Guiana Francesa, Equador, Peru, Bolívia, Paraguai, Uruguai e Brasil: Amapá, Maranhão, Piauí, Pernambuco, Bahia, Mato Grosso, Goiás, Distrito Federal, Minas Gerais, Espírito Santo, Rio de Janeiro, São Paulo, Paraná, Santa Catarina e Rio Grande do Sul.

Trichomanes polypodioides é uma espécie bastante comum em áreas de Mata Atlântica. Caracteriza-se pela lâmina pinatissecta a pinatissecto-pinatífida e presença de tricomas furcados, estrelados, sésseis, às vezes curto-pedunculados, sobre a raque, nervuras, principalmente abaxialmente e sobre as margens da lâmina.

Trichomanes anadromum Rosenst. é considerada distinta de $T$. polypodioides, entretanto as diferenças 


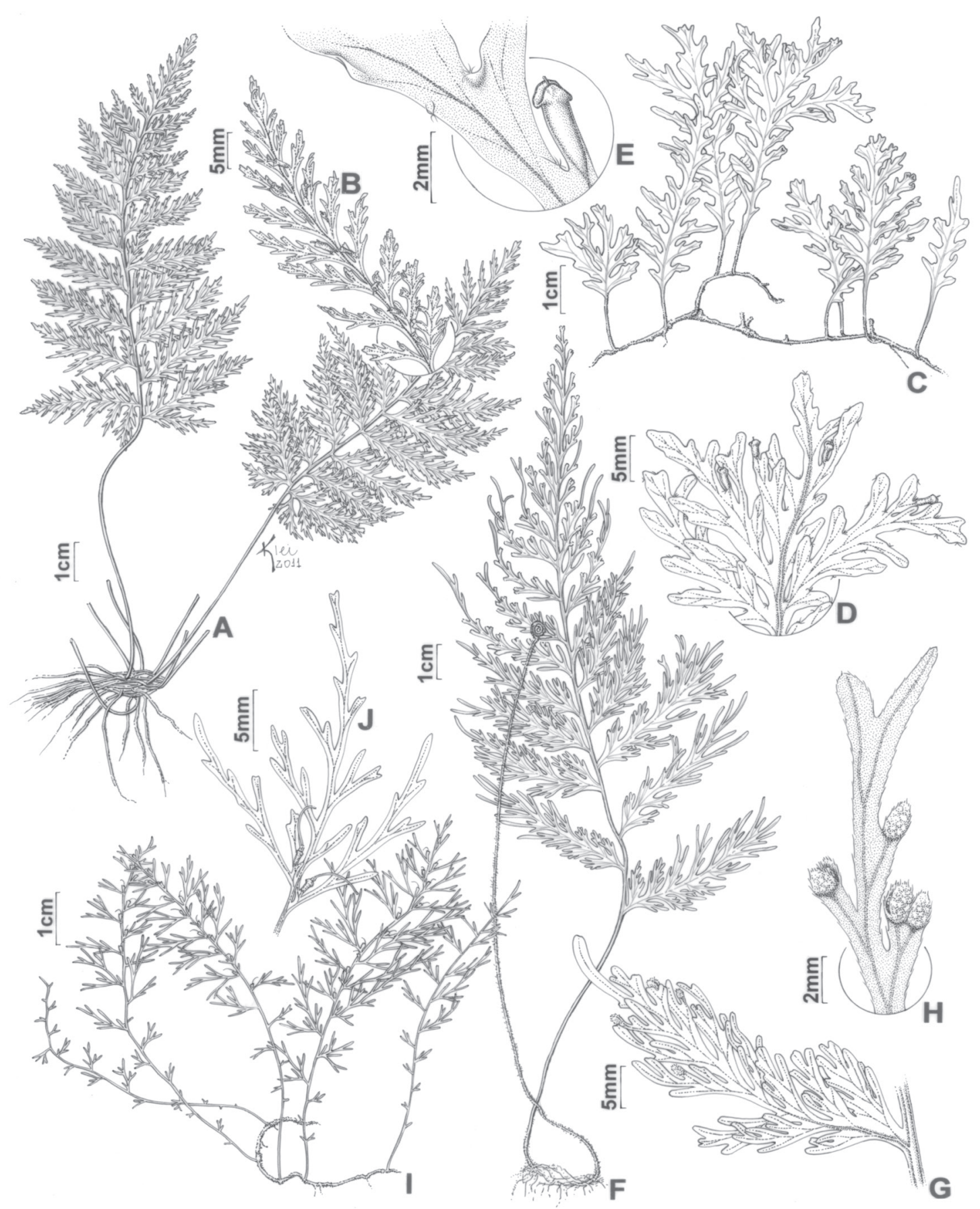

Figura 1. A, B. Abrodictyum rigidum (Corrêa 130). A. Hábito. B. Detalhe do segmento abaxialmente. C - E. Didymoglossum reptans (Handro 246). C. Hábito. D. Detalhe do segmento abaxialmente. E. Indúsio com margem castanho-escura a negra. F - H. Hymenophyllum microcarpum (Hoehne 278 p.p.). F. Hábito. G. Detalhe do segmento adaxialmente. H. Indúsio com tricomas simples na margem. I, J. Polyphlebium angustatum (Prado \& Hirai 2004). I. Hábito. J. Detalhe do segmento abaxialmente.

Figure 1. A, B. Abrodictyum rigidum (Corrêa 130). A. Habit. B. Detail of the segment abaxially. C - E. Didymoglossum reptans (Handro 246). C. Habit. D. Detail of the segment abaxially. E. Indusium with margin dark-brown to blackish. F - H. Hymenophyllum microcarpum (Hoehne 278 p.p.). F. Habit. G. Detail of the segment adaxially. H. Indusium with simple hairs on the margin. I, J. Polyphlebium angustatum (Prado \& Hirai 2004). I. Habit. J. Detail of the segment abaxially 
apontadas na literatura (e.g., Pacheco 1995) se sobrepõem nos espécimes analisados no PEFI.

\section{Vandenboschia Copel.}

Plantas terrestres ou epífitas. Caule longo-reptante, irregularmente ramificado, geralmente robusto, até $1 \mathrm{~mm}$ diâm., com raízes robustas e numerosas, densamente coberto com tricomas, pluricelulares, castanhos a enegrecidos; pecíolo 1-16 cm compr., aglomerados ou irregularmente distantes; lâmina $40 \times 20 \mathrm{~cm}$, oval a linear-oval, 2-pinatissecto-pinatífida a pinada, pinas ou segmentos assimétricos, membranácea a cartácea; pinas ou pínulas anadrômicas; venação anadrômica, falsas vênulas ausentes, margens sem tricomas. Soros com indúsios formados em nervuras laterais das frondes; indúsio cônico, ápice truncado a bilabiado, às vezes expandido, receptáculo longamente exserto.

Vandenboschia ocorre nos trópicos, estendendo-se ao norte em regiões temperadas, com mais de $15 \mathrm{spp}$., distribuídas em dois subgêneros (Lacosteopsis (Prantl) Ebihara \& K. Iwats., Vandenboschia) (Ebihara et al. 2006). De acordo com Windisch (2010), no Brasil ocorrem três espécies e todas podem ser encontradas no Estado de São Paulo.

Vandenboschia radicans (Sw.) Copel., Philipp. J. Sci. 67: 54. $1938 \equiv$ Trichomanes radicans Sw., J. Bot. (Schrader) 1800(2): 97. 1801.

Plantas epífitas. Caule 1,0-1,5 mm diâm., com tricomas levemente aplanados, castanho-escuros a enegrecidos. Frondes 17,0-23,5 cm compr.; pecíolo 1,0-2,5 cm compr., cilíndrico, com ala estreita, com tricomas semelhantes aos do caule; lâmina 15,0-22,0 × 4,0-7,5 cm, lanceolada ou oblongo-lanceolada, 3-pinatissecta, base levemente reduzida, com as pinas proximais um pouco menores do que as medianas; raque alada, com tricomas diminutos semelhantes aos da lâmina; pinas oval-lanceoladas; glabra adaxialmente, com tricomas diminutos, ca. 0,1 mm compr., castanho-avermelhados, sobre as nervuras abaxialmente; últimos segmentos lineares, margens inteiras, ápice arredondado ou emarginado. Indúsio livre ou levemente imerso no tecido laminar, ápice truncado a lobado, margem inteira, glabra.

Material examinado: 20-X-1936, O. Handro s.n. (SP44449, SPF64911).

Distribuição geográfica: Europa, Ásia, África, México, Guatemala, Honduras, El Salvador, Nicarágua,
Costa Rica, Panamá, Grandes e Pequenas Antilhas, Colômbia, Venezuela, Guiana, Suriname, Guiana Francesa, Equador, Peru, Bolívia, Paraguai e Brasil: Roraima, Pará, Amazonas, Bahia, Mato Grosso, Minas Gerais, Espírito Santo, Rio de Janeiro, São Paulo, Paraná, Santa Catarina e Rio Grande do Sul.

Vandenboschia radicans é uma espécie facilmente reconhecida pelo caule longo-reptante, com tricomas castanho-escuros a enegrecidos, frondes 17,0-23,5 cm compr., lâmina 15,0-22,0 × 4,0-7,5 cm, lanceolada ou oblongo-lanceolada, 3-pinatissecta e é a única espécie do gênero ocorrendo na área do PEFI. A espécie mais semelhante é $V$. collariata (Bosh) Ebihara \& K. Iwats., que difere por ter indúsio com ápice expandido, levemente revoluto (Mickel \& Smith 2004).

\section{Agradecimentos}

Ao CNPq pela concessão da Bolsa de Produtividade em Pesquisa (do segundo autor) e auxílio para este projeto (processo 300843-93-3).

\section{Literatura citada}

Boldrin, A.H.L. \& Prado, J. 2007. Pteridófitas terrestres e rupícolas do Forte dos Andradas, Guarujá, São Paulo, Brasil. Boletim de Botânica da Universidade de São Paulo 25: 1-69.

Ebihara, A., Dubuisson, J.-Y., Iwatsuki, K., Hennequin, S. \& Ito, M. 2006. A Taxonomic revision of Hymenophyllaceae. Blumea 51: 221-280.

Fidalgo, O. \& Bononi, V.L.R. (coords.). 1984. Técnicas de coleta, preservação e herborização de material botânico. Manual 4. Instituto de Botânica, São Paulo.

Hoehne, F.C., Kuhlmann, M. \& Handro, O. 1941. O Jardim Botânico de São Paulo. Secretaria da Agricultura, Indústria e Comércio, Departamento de Botânica do Estado, São Paulo.

Iwatsuki, K. 1984. A scheme of classification based chiefly on the Asiatic species. Acta Phytotaxonomica et Geobotanica 35: 165-179.

Iwatsuki, K. 1990. Hymenophyllaceae. In: K.U. Kramer \& P.S. Green (eds.). The families and genera of vascular plants, v. 1, Pteridophytes and Gymnosperms. SpringerVerlag, Berlin, pp. 157-163.

Kramer, K.U. \& Green, P.S. 1990. The families and genera of vascular plants, v. 1, Pteridophytes and Gymnosperms. Springer-Verlag, Berlin.

Melhem, T.S., Giulietti, A.M., Forero, E., Barroso, G.M., Silvestre, M.S.F., Jung, S.L., Makino, H., Melo, M.M.R.F., Chiea, S.C., Wanderley, M.G.L., Kirizawa, M. \& Muniz, C. 1981. Planejamento para elaboração da "Flora Fanerogâmica da Reserva do Parque Estadual das Fontes do Ipiranga (São Paulo, Brasil)". Hoehnea 9: 63-74. 
Mickel, J.T. \& Smith, A.R. 2004. The Pteridophytes of Mexico. Memoirs of the New York Botanical Garden 88: 1-1055.

Milanez, A.I., Bicudo, C.E.M., Vital, D.M. \& Grandi, R.A.P. 1990. Criptógamos do Parque Estadual das Fontes do Ipiranga, São Paulo, SP: Planejamento. Hoehnea 17: 43-49.

Nóbrega, G.A. \& Prado, J. 2008. Pteridófitas da vegetação nativa do Jardim Botânico Municipal de Bauru, Estado de São Paulo, Brasil. Hoehnea 35: 7-55.

Pacheco, L. 1995. Trichomanes L. In: R.C. Moran \& R. Riba (eds.). Psilotaceae a Salviniaceae. In: G. Davidse, M.S. Sousa \& S. Knapp (eds.). Flora Mesoamericana. Universidade Nacional Autónoma de México, Ciudad de México, v. 1, pp. 71-83.

Pichi-Sermolli, R.E.G. 1996. Authors of scientific names in Pteridophyta. Royal Botanic Gardens, Kew.

Prado, J. 2004a. Criptógamos do Parque Estadual das Fontes do Ipiranga, São Paulo, SP. Pteridophyta: chave para as famílias; 2. Blechnaceae. Hoehnea 31: 1-10.

Prado, J. 2004b. Criptógamos do Parque Estadual das Fontes do Ipiranga, São Paulo, SP. Pteridophyta: 6. Dicksoniaceae. Hoehnea 31: 239-242.

Prado, J. 2004c. Criptógamos do Parque Estadual das Fontes do Ipiranga, São Paulo, SP. Pteridophyta: 14. Ophioglossaceae. Hoehnea 31: 171-174.

Prado, J. 2004d. Criptógamos do Parque Estadual das Fontes do Ipiranga, São Paulo, SP. Pteridophyta: 17. Pteridaceae. Hoehnea 31:39-49.

Prado, J. 2004e. Criptógamos do Parque Estadual das Fontes do Ipiranga, São Paulo, SP. Pteridophyta: 8. Gleicheniaceae. Hoehnea 31: 33-37.

Prado, J. 2004f. Criptógamos do Parque Estadual das Fontes do Ipiranga, São Paulo, SP. Pteridophyta: 5. Dennstaedtiaceae. Hoehnea 31: 11-22.

Prado, J. 2004g. Criptógamos do Parque Estadual das Fontes do Ipiranga, São Paulo, SP. Pteridophyta: 15. Osmundaceae. Hoehnea 31: 93-96.

Prado, J. 2004h. Pteridófitas do Maciço da Juréia. In: O.A.V. Marques \& W. Duleba (eds.). Estação Ecológica Juréia-Itatins. Ambiente físico, flora e fauna. Editora Holos, Ribeirão Preto, São Paulo, pp. 139-151.

Prado, J. 2006a. Criptógamos do Parque Estadual das Fontes do Ipiranga, São Paulo, SP. Pteridophyta: 18. Salviniaceae. Hoehnea 33: 107-110.
Prado, J. 2006b. Criptógamos do Parque Estadual das Fontes do Ipiranga, São Paulo, SP. Pteridophyta: 12. Lophosoriaceae. Hoehnea 33: 123-126.

Prado, J. \& Hirai, R.Y. 2008. Criptógamos do Parque Estadual das Fontes do Ipiranga, São Paulo, SP. Pteridophyta: 13. Lycopodiaceae e 20. Selaginellaceae. Hoehnea 35: 543-552.

Prado, J. \& Hirai, R.Y. 2010. Criptógamos do Parque Estadual das Fontes do Ipiranga, São Paulo, SP. Pteridophyta: 21. Tectariaceae. Hoehnea 37: 367-376.

Prado, J., Hirai, R.Y. \& Schwartsburd, P.B. 2010. Criptógamos do Parque Estadual das Fontes do Ipiranga, São Paulo, SP. Pteridophyta: 9. Grammitidaceae e 16. Polypodiaceae. Hoehnea 37: 445-460.

Prado, J. \& Labiak, P.H. 2009. Pteridófitas. In: M.I.M.S. Lopes, M. Kirizawa \& M.M.R.F. Melo (orgs.). Patrimônio da Reserva Biológica do Alto da Serra de Paranapiacaba: a antiga Estação Biológica do Alto da Serra. Instituto de Botânica, São Paulo, pp. 269-289.

Salino, A. 1996. Levantamento das pteridófitas da Serra do Cuscuzeiro, Analândia, SP, Brasil. Revista Brasileira de Botânica 19: 173-178.

Salino, A. \& Almeida, T.E. 2008. Pteridófitas do Parque Estadual de Jacupiranga, SP, Brasil. Acta Botanica Brasilica 22: 983-991.

Smith, A.R., Pryer, K.M., Schuettpelz, E., Korall, P., Schneider, H. \& Wolf, P.G. 2006. A classification for extant ferns. Taxon 55: 705-731.

Smith, A.R., Pryer, K.M., Schuettpelz, E., Korall, P., Schneider, H. \& Wolf, P.G. 2008. Fern classification. In: T.A. Ranker \& C.H. Haufler (eds.). Biology and evolution of ferns and lycophytes. Cambridge University Press, Cambridge, pp. 417-467.

Tryon, R.M. \& Tryon, A.F. 1982. Ferns and allied plants, with special reference to tropical America. Springer Verlag, New York.

Windisch, P.G. 2010. Hymenophyllaceae. In: R.C. Forzza, J.F. Baumgratz, C.E. M, Bicudo, D. Canhos, A.A. Carvalho Jr., A. Costa, D.P. Costa, M. Hopkins, M.P. Leitman, L.G. Lohmann, E.N. Lughadha, L.C. Maia, G. Martinelli, M. Menezes, M.P. Morin, M. Nadruz, A.L. Peixoto, J.R. Pirani, J. Prado, L.P. Queiroz, S. de Souza, V.C. Souza, J.R. Stehmann, L.S. Sylvestre, B.M.T. Walter \& D.C. Zappi (eds.). Catálogo de Plantas e Fungos do Brasil. Jardim Botânico do Rio de Janeiro, Rio de Janeiro, v. 1, pp. 538-540. 